\title{
XXX. On the determination of the distance of a given point on the earth's surface at, or very near, the level of the sea, by observations on its depression from a known height above it
}

\section{William Galbraith Esq. F.R.A.S.}

To cite this article: William Galbraith Esq. F.R.A.S. (1844) XXX. On the determination of the distance of a given point on the earth's surface at, or very near, the level of the sea, by observations on its depression from a known height above it, Philosophical Magazine Series 3, 24:158, 181-185, DOI: $10.1080 / 14786444408644831$

To link to this article: http://dx.doi.org/10.1080/14786444408644831

\section{Published online: 30 Apr 2009.}

Submit your article to this journal ¿

\section{Article views: 2}



Of the lodes yielding both tin and copper ores . . . $37 \cdot 2$ of all the lodes the proportion heaved towards the righthand is . . . . . . . . . . . . . . . $51 \cdot 1$ Of the tin lodes . . . . . . . . . . . . . . . . . $566^{\circ}$ ... lodes yielding both tin and copper ores . . . $44 \cdot 0$ ... copper lodes . . . . . . . . . . . . 524

Of all the lodes the proportion heaved towards the lefthand is . . . . . . . . . . . . , 26.2

Of the tin lodes . . . . . . . . . . . . . . 260 ... lodes yielding both tin and copper ores . . . 18.6 ... copper lodes. . . . . . . . . . . . 29.8

Of all the lodes the proportion heaved towards the greater angle is . . . . . . . . . . . . . . 63.5

Of the tin lodes . . . . . . . . . . . . . . . 520

... lodes yielding both tin and copper ores . . . 56.0

... copper lodes . . . . . . . • . • . . . . • • • $74 \cdot 2$

Of all the lodes the proportion heaved towards the smaller angle is . . . . . . . . . . . . 12.9

Of the tin lodes . . . . . . . . . . . . . . .

... lodes yielding both tin and copper ores . . . $6 \cdot 8$

... copper lodes. . . . . . . . . . . . $8 \cdot 8$

The mean distance of the heaves feet.

Of all the lodes is . . . . . . . . . . . . 164

... tin lodes . . . . . . . . . . . . . 154

... lodes yielding both tin and copper ores . . $14 \cdot 6$

... copper lodes . . . . . . . . . . . $17 \cdot 5$

Towards the right-hand . . . . . . . . . 18.7

... left-hand . . . . . . . . . . . $12 \cdot 0$

... greater angle . . . . . . . . . 16.3

Gongo Soco Gold Mines, Brazil, W. J. Henwood. October 5,1843 .

XXX. On the Determination of the Distance of a given point on the Earth's Surface at, or very near, the level of the sea, by observations on its depression from a knoton height above it. By William Galbraith, Esq., F.R.A.S.

To the Editors of the Philosophical Magazine and Journal. Gentlemen,

SHOULD the inclosed short paper meet with your approbation, you will oblige me by giving it a place in your Journal. It is intended as an improved solution of that problem in Horsburgh's edition of Mackenzie's Treatise on Marine 


\section{$182 \mathrm{Mr}$. Galbraith on the Determination of Distances}

Surveying, in which both the effects of curvature and refraction are neglected, that in considerable distances are indispensable where even tolerable accuracy is required. I have occasionally found it useful, and others may probably also find it so.

I am, Gentlemen,

54 South Bridge, Edinburgh,

Your obedient Servant,

December 28, 1843 .

William Galbraith.

1. Let $\mathrm{BHF}$ be a section of the earth, $\mathrm{A} B$ the given height, the angle $\mathrm{E} \mathrm{A} \mathrm{H}$, and $\mathrm{B} \mathrm{H}$ the required distance.

In the triangle $A B I$ right-angled at $B$, there are given $A B$, the height of the point $A$ above $B$, the earth's surface at the mean level of the sea $B$ HF, and the angle B A I, the complement of the angle of depression E A H.

Now let the height be denoted by $h$ and the depression by $D$, then $R: \cot D$ $:: h: \mathrm{BI}=\cot \mathrm{D} \times h$, a first approximation to the distance $\mathrm{B} \mathrm{H}$ or $\mathrm{K}$, the chord in this instance nearly when not great, or a small part of the distance of the visible horizon only.

But $\mathrm{IBH}=\mathrm{MHB}=\mathrm{HFB}=\frac{1}{2} \mathrm{HCB}$, of which an approximate value may be found from that of $B I$, when neither the height nor distance is great. For this purpose let $\rho$ be the radius of the earth as usual, $R^{\prime \prime}$ an arc equal to the radius in

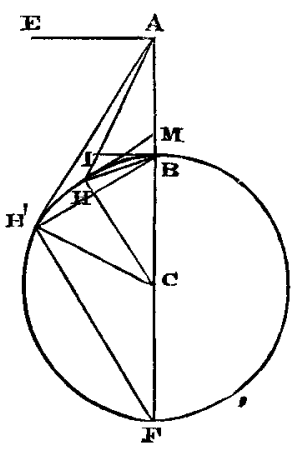
seconds, and $A^{\prime \prime}$ the arc in seconds which measures the angle H F B, then

$$
\mathrm{A}^{\prime \prime}=\frac{\mathrm{R}^{\prime \prime}}{2 \rho} \cot \mathrm{D} \cdot h \text { nearly }
$$

In the triangle $\mathrm{A} B \mathrm{~B}$, the angle $\mathrm{A} H \mathrm{H}=\mathrm{A}$ I $\mathrm{B}=\mathrm{D}-\mathrm{A}^{\prime \prime}$. Again, in the triangle A B $, \sin A H B: \sin H A B:: A B$ : $\mathrm{B} \mathrm{H}=\mathrm{K}$,

or $\mathrm{K}=\operatorname{cosec} \mathrm{AHB} \sin \mathrm{HAB} \cdot \mathrm{AB}=\operatorname{cosec}\left(\mathrm{D}-\mathrm{A}^{\prime \prime}\right) \cos \mathrm{D} . h$ (2.)

The effect of refiaction is expressed by $n \mathrm{~K}$ or $2 n \mathrm{~A}^{\prime \prime}, n$ being the coefficient of refraction, a quantity by which $D$ must be increased.

$$
\begin{aligned}
& \mathrm{D}-\mathrm{A}^{\prime \prime}+2 n \mathrm{~A}^{\prime \prime}=\mathrm{D}-\left(1-2 n \mathrm{~A}^{\prime \prime}\right)=\mathrm{D}-(0.5-n) \mathrm{A}^{\prime \prime} \\
& \text { Putting } a^{\prime \prime}=(0.5-n) \mathrm{A}^{\prime \prime} \ldots,(x) \text {, } \\
& \text { then } \quad 2 n \mathrm{~A}^{\prime \prime}=\frac{n}{0.5-n} a^{\prime \prime}=\alpha^{\prime \prime} \ldots(7 .) \quad . \quad . \quad \text {. }
\end{aligned}
$$

Substituting these in formula (2.), and it becomes

$$
\mathrm{K}=\operatorname{cosec}\left(\mathrm{D}-a^{\prime \prime}\right) \cos \left(\mathrm{D}+\alpha^{\prime \prime}\right) h . . .
$$


It is obvious also that

$$
a^{\prime \prime}=(0.5-n) \frac{\mathrm{R}^{\prime \prime}}{\varrho} \mathrm{K}=(0.5-n) f \mathrm{~K}, . . .
$$

in which $f$ is the factor to convert feet on the earth's surface into seconds of arc in any given direction.

2. Formula (1.) fails to determine $A^{\prime \prime}$ with sufficient accuracy when the height $h$ is considerable, and the distance $K$ extends to, or near to, the visible horizon.

In this case we may proceed as follows:-

B C : A C : : $\sin H$ A C $: \sin A$ H C $=\frac{A C}{B C} \sin H$ A C.

Whence $\quad 180^{\circ}-(\mathrm{A} \mathrm{HC}+\mathrm{H} \mathrm{A} \mathrm{C})=\mathrm{H} \mathrm{C} \mathrm{A}$,

and

Wherefore

$\frac{1}{8} \mathrm{HCB}=\mathrm{H} \mathrm{FB}=\mathrm{IBH}=\mathrm{A}^{\prime \prime}$.

$$
\varrho: \rho+h:: \cos \mathrm{D}: \sin \mathrm{AHC}=\left(1+\frac{h}{\rho}\right) \cos \mathrm{D} \text {. }
$$

But $h$ being very small in comparison with $\rho, 1+\frac{h}{\rho}$ exceeds unity by a very small fraction, therefore $\log \left(1+\frac{h}{\rho}\right)=\frac{\mu h}{\rho}$, in which $\mu$ is the logarithmic modulus. If $\rho$ be taken equal to the radius of the equator as a mean value, then $\log \left(1+\frac{h}{\rho}\right)$ $=\overline{8} \cdot 3171678$. Instead of the mean value of $\rho$ being taken as above,

Hence $\quad \log \operatorname{sine} \mathrm{AHC}=\log \cos \mathrm{D}+\frac{\mu}{\rho} h .$.

$$
\log \varrho=\log \mathrm{R}^{\prime \prime}-\log f \text { exactly . . . (7.) }
$$

always obtuse, of which in this problem its excess above $90^{\circ}$ is taken.

In the preceding formula it is supposed that the coefficient of refraction, $n$, is determined by observation or calculation. The mean value, however, amounting to 0.08 of the intercepted arc, will frequently be sufficient. In this case the effect will be $0.08 \mathrm{~K}$, or $0.16 \mathrm{~A}^{\prime \prime}$, a quantity to be added to $\mathrm{D}$ while $\mathrm{A}^{\prime \prime}$ must be subtracted.

Hence $\mathrm{D}-\mathrm{A}^{\prime \prime}+0.16 \mathrm{~A}^{\prime \prime}=\mathrm{D}-0.84 \mathrm{~A}^{\prime \prime}=\mathrm{D}-a^{\prime \prime}$,

by making

$$
a^{\prime \prime}=0.84 \mathrm{~A}^{\prime \prime} \text {. }
$$

Recurring to formula (1.), by substitution we have

$$
\log a^{\prime \prime}=\text { const. } \log 7 \cdot 6170579+\log \cot \mathrm{D}+\log h \text {. }
$$

But $a^{\prime \prime}=\frac{n}{0.5-n} a^{\prime \prime}=\frac{0.08}{0.42} a^{\prime \prime}=0.1904762 a^{\prime \prime}=\frac{1}{5} a^{\prime \prime}$ nearly. 


\section{Mr. Galbraith on the Determination of Distances}

By combining this with the former, there results

first const. $\log 7 \cdot 6170579+\log$ of $0 \cdot 1904.762=6 \cdot 8968986$

\section{Hence}

$=$ the second constant logarithm.

$$
\begin{aligned}
& \log a^{\prime \prime}=1 \text { st const. } \log 7 \cdot 6170579+\log K \\
& \log \alpha^{\prime \prime}=2 \text { nd const. } \log 6.8968986+\log K,
\end{aligned}
$$

which two results being substituted in formula (4.), and the operation repeated, will give $\mathrm{K}$ sufficiently correct, when the distance is only a small, or even a moderate part of that of the visible horizon.

In practice it will be found convenient and sufficiently accurate to use the mean quantities in the first and second approximations, and the true quantities under given circumstances for the last approximation only.

3. Again, let the angle $\mathrm{A} \mathrm{H} \mathrm{C}$ be denoted by $\mathrm{H}$, and $\sin \mathrm{H}$ $=2 \sin \frac{1}{2} H \cos \frac{1}{2} H=2 \sin \frac{1}{2} H\left(1-\sin ^{2} \frac{1}{2} H\right)^{\frac{1}{2}}$, therefore

$$
2 \sin \frac{1}{2} \mathrm{H}\left(1-\sin ^{2} \frac{1}{2} \mathrm{H}\right)^{\frac{1}{2}}=\frac{\rho+h}{\rho} \cos \mathrm{D} \text {. }
$$

Squaring both sides, and there results

or, by arranging,

$$
4 \sin ^{2} \frac{1}{2} \mathrm{H}-4 \sin ^{4} \frac{1}{2} \mathrm{H}=\left(\frac{\rho+h}{\rho}\right)^{2} \cos ^{2} \mathrm{D},
$$

$$
4 \sin ^{4} \frac{1}{2} \mathrm{H}-4 \sin ^{2} \frac{1}{2} \mathrm{H}=-\left(\frac{\rho+h}{\rho}\right)^{2} \cos ^{2} \mathrm{D} \text {. }
$$

Add 1 to each side of the equation, and

$$
4 \sin ^{4} \frac{1}{2} H-4 \sin ^{2} \frac{1}{2} H+1=1-\left(\frac{\rho+h}{\rho}\right)^{2} \cos ^{2} \mathrm{D} \text {, }
$$

or $4 \sin ^{4} \frac{1}{2} \mathrm{H}-4 \sin ^{2} \frac{1}{2} \mathrm{H}+1=\left(1+\frac{\rho+h}{\rho}\right) \cos \mathrm{D}$

$$
\times\left(1-\frac{\rho+h}{\rho}\right) \cos \mathrm{D} \text {. }
$$

Multiplying and dividing by $\left(\frac{\rho+h}{\rho}\right)^{2}$, and

$$
\text { 4. } \begin{aligned}
\sin ^{4} & \frac{1}{2} \mathrm{H}-4 \sin ^{2} \frac{1}{2} \mathrm{H}+1 \\
\quad= & \left(\frac{\rho+h}{\rho}\right)^{2}\left(\frac{\rho}{\rho+h}+\cos \mathrm{D}\right)\left(\frac{\rho}{\rho+h}-\cos \mathrm{D}\right) .
\end{aligned}
$$

But $\frac{\rho+h}{\rho}=\sec D_{1}, D_{,}$being the depression of the horizon, $4 \sin ^{4} \frac{1}{2} \mathrm{H}-4 \sin ^{2} \frac{1}{2} \mathrm{H}+1=\sec ^{2} \mathrm{D}_{2}\left(\cos \mathrm{D}_{1}+\cos \mathrm{D}\right)\left(\cos \mathrm{D}_{1}-\cos \mathrm{D}\right)$. Since $\left(\cos \mathrm{D}_{i}+\cos \mathrm{D}\right)\left(\cos \mathrm{D}_{1}-\cos \mathrm{D}\right)=\sin \left(\mathrm{D}+\mathrm{D}_{i}\right) \sin \left(\mathrm{D}-\mathrm{D}_{l}\right)$ $4 \sin ^{4} \frac{1}{2} \mathrm{H}-4 \sin ^{2} \frac{1}{2} \mathrm{H}+1=\sec ^{2} \mathrm{D}_{l}\left\{\sin \left(\mathrm{D}+\mathrm{D}_{l}\right) \sin \left(\mathrm{D}-\mathrm{D}_{l}\right)\right\}$. 
Extracting the square root, and there results $2 \sin ^{2} \frac{1}{2} \mathrm{H}-1= \pm \sec \mathrm{D}_{l}\left\{\sin \left(\mathrm{D}+\mathrm{D}_{\imath}\right) \sin \left(\mathrm{D}-\mathrm{D}_{l}\right)\right\}^{\frac{1}{2}}$. $2 \sin ^{2} \frac{1}{2} \mathrm{H}=1 \pm \sec \mathrm{D}_{1}\left\{\sin \left(\mathrm{D}+\mathrm{D}_{\imath}\right) \sin \left(\mathrm{D}-\mathrm{D}_{1}\right)\right\}^{\frac{1}{2}}$, and $\sin \frac{1}{2} H=\left\{\frac{1}{2}\left(1 \pm \sec D_{l}\left[\sin \left(D+D_{l}\right) \sin \left(D-D_{l}\right)\right]^{\frac{1}{2}}\right)\right\}^{\frac{1}{2}}$. (13.) From formula (16.) it appears that $\mathrm{H}-90^{\circ}=2 \sin ^{2} \frac{1}{2} \mathrm{H}-1$, the radius, or $\sin 90^{\circ}$ being unity, therefore calling $\mathrm{H}-90^{\circ}$ $=d$, we have

$$
\sin d=\sec \mathrm{D}_{1}\left\{\sin \left(\mathrm{D}+\mathrm{D}_{l}\right) \sin \left(\mathrm{D}-\mathrm{D}_{1}\right)\right\}^{\frac{1}{2}} .
$$

the most useful form, since $d$ in this case is the arc required.

Remarks.-1. If the negative sign in formula (13.) be employed, the resulting value of $H$ will be the supplement of that by the positive.

2. Since $D$ is the depression of the given point, and $D$, that of the horizon, $\mathbf{D}-\mathbf{D}$, will then be the difference between the depression of the given point $\mathrm{D}$ and that of the horizon $\mathrm{D}_{\text {, }}$, which difference may be measured with a sextant or reflecting circle, while the depression of the horizon may be computed by the usual formulæ; and then $D$ and $D-D$, become known without an altitude circle on shore, as required in the first method.

3. From the same figure the method of determining the height above the level of the sea may be very readily derived.

Let $\mathrm{H}^{\prime}$ be the visible horizon, the angle $\mathrm{E} \mathrm{A} \mathrm{H}=\mathrm{D}$ the depression, $A \mathrm{H}^{\prime}$ a tangent to the horizon at $\mathrm{H}^{\prime}$ passing through the point of observation $\mathrm{A}$, and $\mathrm{AB}=h$, the required height.

From the property of the circle $\mathrm{EAH}^{\prime}=\mathrm{H}^{\prime} \mathrm{CA}=2 \mathrm{H}^{\prime} \mathrm{FD}$, and $H^{\prime} \mathrm{F} \mathrm{B}=\frac{1}{2} \mathrm{D}$. The triangles $\mathrm{AB} \mathrm{H}, \mathrm{H}^{\prime} \mathrm{B} F$ give

and

$$
\sin \frac{1}{2} \mathrm{D}: \cos \mathrm{D}:: \mathrm{AB}: \mathrm{B} \mathrm{H}^{\prime}=\mathrm{AB} \times \frac{\cos \mathrm{D}}{\sin \frac{1}{2} \mathrm{D}^{\prime}}
$$

$$
\begin{aligned}
\sin \mathrm{D}: & \cos \frac{1}{2} \mathrm{D}:: \mathrm{B} \mathrm{H}^{\prime}: \mathrm{H}^{\prime} \mathrm{C}=\mathrm{AB} \times \frac{\cos \mathrm{D} \cos \frac{1}{2} \mathrm{D}}{\sin \mathrm{D} \sin \frac{1}{2} \mathrm{D}} \\
& =\mathrm{A} \mathrm{B} \cot \mathrm{D} \cot \frac{1}{2} \mathrm{D} .
\end{aligned}
$$

Whence $h=\mathrm{H}^{\prime} \mathrm{C} \tan \mathrm{D} \tan \frac{1}{2} \mathrm{D}=\frac{1}{9} \rho \tan ^{2} \mathrm{D}$ nearly (15.) Introducing the effects of refraction, $n$,

when the dip is expressed in seconds and $n=0.08$,

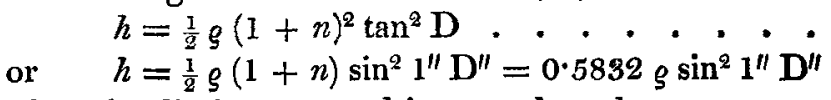

$$
\text { const. } \log \text { or } \log \text { of } 0.5832 \varrho \sin ^{2} 1^{\prime \prime}=6.457582 \text {. }
$$

